\title{
Trials of the gluttons for punishment
}

\section{Harold McGee}

Never Satisfied: A Cultural History of Diets, Fantasies and Fat. By Hillel Schwartz. Free Press, New York/Collier Macmillan, London:1987. Pp.468. \$19.95, £14.95.

For Lord Byron it was hard biscuits, soda water sans hock and vinegar-drenched potatoes. For Louis Armstrong it was orange juice, antacids and laxatives. For Henry James it was "fletcherizing": slowly chewing the flavour out of each mouthful, which in the case of a shallot could take seven minutes. "Grapple it to your soul with hoops of steel", he wrote a friend (though five years later he would complain of a persistent "stomachic crisis: the condition of more and more sickishly loathing food"). Even today a distant echo of "The Great Masticator" Horace Fletcher can be heard issuing from an electronic scale "with a General Instrument voice synthesizer, $400 \mathrm{k}$ bits of $\mathrm{ROM}$ memory and a Hitachi microprocessor, saying 'Congratulations, I am pleased. You are making progress. Today practice taking more time to chew each mouthful'."

Hillel Schwartz's entertaining book is replete with anecdotes and curious, sometimes appalling facts from the history, mainly American, of weight-reducing regimens. The first systematic American scale-watchers, around 1835, were followers of the Reverend Sylvester Graham who felt obliged to prove that they would not lose weight on a temperate and vegetarian diet. Only at the turn of the century did slimness become desirable, and remedies formerly deployed against dyspepsia were turned against newly unwanted fat.

The quantification of nutrition was pioneered at about the same time by the chemist W. O. Atwater, who analysed and published the protein, carbohydrate and fat contents of common American foods. Beginning in 1904, menus at the sanatorium run by $\mathbf{J}$. H. Kellogg, the inventor of corn flakes, gave calorie counts for each dish, and in 1906 the Yale economist and amateur gymnast Irving Fisher suggested replacing the ounce with 100 large (kilo-) calories as the standard serving measure. By the time of the First World War caloriecounting had been incorporated into several popular diet books. Kitchen scales were introduced in the $1920 \mathrm{~s}$, a couple of decades after bath scales.

Because it requires no active intervention of will power, an attractive alternative to caloric restriction has been pharmacological tinkering with metabolism. lodine in the form of the seaweed Fucus was discovered as a reducing agent in 1859 , and thyroid extract in 1883 ; both were incorporated into obesity cures early in the next century. Dinitrophenol, which uncouples oxidative phosphorylation and dissipates energy stores as heat, was tremendously popular in the 1930 s despite having been recognized as a toxin in munitions factories; it was banned in 1938. Ready to take its place was benzedrine, originally marketed as an asthma remedy, and the first of the amphetamines to be used for appetite suppression, even in

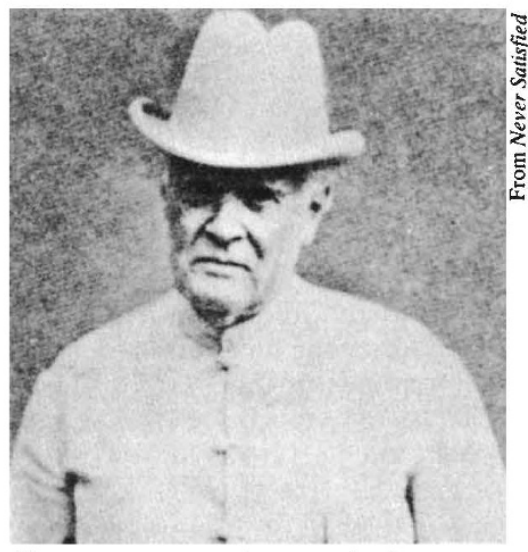

Chewing guru - Horace Fletcher, "The Great Masticator", whose white clothing reflected an equal concern with intestinal asepsis.

two-year-olds. The digestive equivalent of contraception was proposed in 1977 by two physicians who discovered that perfluoroctyl bromide, a fluorocarbon used as a radiological contrast material, can coat the intestinal mucosa and limit nutrient absorption.

Never Satisfied is a lively and valuable contribution to the history of American foodways. Schwartz has gathered a massive amount of material from the popular, medical and historical literatures, and his book is exhaustively documented; a reference is given for nearly every sentence. He reconstructs what he calls the "shared fictions of the body" that have prevailed over the past 150 years, and demonstrates the contributions of chemists and physiologists, economists and insurance companies. He brings order to the bewildering variety of diets, sorting them by rationale and pointing out frequent recurrences, the "blue-smoke and trap-door entrances and exits".

Schwartz also aims to explain "the cultural fit between shared fictions of the body and the reducing methods of the era", but generally I find these correlations hard to swallow. The problem is that many methods co-existed in each era. For example, Schwartz describes fasting, slow-chewing, calorie-counting and thyroid pills as four contemporaneous methods that "dealt with gluttony and fatness as if they were problems of flow" in a body characterized by "dynamic balance". Looked at less abstractly, they seem most remarkable for their differences. One could eat next to nothing or moderately or well; one exercised one's self-control, jaw muscles, arithmetic or thyroid gland; food was a forbidden temptation, a raw material in need of processing, a set of numbers or fuel to be burned. As Schwartz candidly admits at one point, "The truth was a mess. People set out to lose weight any way they could, regardless of compulsive historians, and they mixed everything up".

Schwartz's principal thesis is that slimming

is the modern expression of an industrial society confused by its own desires and therefore never satisfied. On the one hand we seem to want more of everything; on the other hand we are suspicious of surplus. Increasingly perplexed or intimidated by abundance, Americans have taken the protocols of slimming as the protocols for social and spiritual renewal.

Surprisingly little evidence is mustered in support of this proposition. Schwartz does locate the turn towards slimness during a period of economic overproduction and underconsumption, but he gives just as much credit to the "kinaesthetic" examples set by airplane pilots, efficiency experts and Isadora Duncan:

The modern dancers in the long run had probably the greatest effect, as their principles of movement became part of the cinematic code and established the standards for the motor education of most young children.

This important assertion also stands unsupported.

A more complete analysis of the appeal of slimming would place such regimens in the broader context of American health and diet fads. Lacking entrenched national traditions in belief or in social structure, the New World seems to have encouraged an optimistic sense that renewal, personal as well as "social and spiritual", was possible, but also an anxiety about seeing such renewal come to pass. In religion, this outlook fostered a great variety of sects, including several that proclaimed the imminent return of Christ. In dietary matters, abetted by the lack of a strong, unifying culinary tradition, it fostered a susceptibility to regimens that promised perfect health and long life. Such regimens flourished long before the triumph of slimness, and surely helped prepare the way.

A comparison of dietary trends in the New and Old Worlds would have brought these and other factors into relief. Schwartz quotes the joke, originally aimed at the English, of an early French visitor: "What a country! Fifty religions and only one sauce - melted butter!". By contrast, Catholic, generously sauced France resisted dietary change. A 1909 French textbook of domestic science, paraphrased 
by the historian Theodore Zeldin

pointed out the danger of over-rich sauces, but insisted nevertheless that everybody should know how to prepare them and that no dinner was complete without them; the serving of appetising food, its artistic preparation and display were held up as one of the most important duties of every housewife.

Stephen Mennell, a sociologist, has pointed out that English cookery columns for the lower-middle classes "emphasized the need to eat fat and heavy food for body-building", and French women's magazines began calorie-counting only in the 1950s. "Abundance" or affluence is clearly part of the story, but not the whole story.

Schwartz's treatment of the role of science and medicine in dietary faddism is disappointingly sketchy. As he demonstrates, scientific findings have repeatedly provided the raw material for new fads; and many of the more egregious regimens have been and continue to be concocted by medical doctors. One would like to know how it has been that technical advances have found their way into the popular imagination. Who has done the bending to fit them to the desire for a panacea? Why have "health food" stores come to stock capsules of soy phosphatides, chelated copper and L-phenylalanine alongside their "organic" lettuce? Unfortunately, Schwartz finishes by lumping physiologists together with evangelical
Christian dieters (More of Jesus and Less of $\mathrm{Me}$ ) and "behaviourists" (How to Be a Winner at the Weight Loss Game), all of them having "drawn obesity away from the perturbing social and economic issues of consumption". The neurophysiologists "hoped" to do this "by drawing appetite deep inside the brain". This is a novel species of scientific motivation.

Never Satisfied does not conclude with a straightforward account of current views on body weight and health, or on the amenability of weight to dietary manipulation. Perhaps Schwartz feels that today's answers are still provisional and will be out of fashion tomorrow. Instead, the last chapter opens with an all-out diatribe against slimming, complete with such remarks as "few militarists, murderers, or rapists are fat". This turns out to be a calculated exercise in imagining a future manifesto of the Fat Power movement, and the last pages note some current signs of discontent with the culture of thinness. Neither the author nor his reader finishes fully satisfied. Still, Schwartz is to be thanked for laying on quite a spread as he vividly reminds us that "Our bodies and our foods are as much social constructs as they are proteins, carbohydrates, fats". $\square$

Harold McGee, 838 La Jennifer Way, Palo Alto, California 94306, USA, is author of On Food and Cooking: The Science and Lore of the Kitchen, published in the United States by Charles Scribner's Sons and in Britain by Allen \& Unwin.

\section{Fearful symmetry}

\section{David R. Rosseinsky}

Symmetry Through the Eyes of a Chemist. By István Hargittai and Magdolna Hargittai. VCH:1986. Pp.458. DM156, \$90.30.

THE COMMON problem in early winter, of finding two left- or right-handed gloves, would be instantly resolved by dropping the arbitrariness in mitt design of differentiating interiors from exteriors. The inside-out remedy here is perhaps the only everyday inversion not drawn on by the authors in their lead-in to symmetry in science.

While Blake's Tiger! Tiger! is also missing, his God as Geometer provides a typical illustration, and Escher's obsessive collocations are yet again called upon. But many of the everyday illustrations are photographs of carefully observed, basically commonplace scenes picked out for some symmetric facet: the snowflake gets 10 pages. These examples provide a beguilingly attractive introduction, especially to the minority of readers deficient in three-dimensional perception (personal research shows us even to be perhaps a silent majority). Such a utilitarian assessment undervalues the aesthetic pleasure to be derived from the arrays of examples of symmetry in art, sculpture and nature. Progress towards the general introduction of symmetry labels and symmetry operations follows naturally, together with their application to chemical systems.

Conical (conical?) periodic tables have however already featured in the introduction, and 1,2,dibromo-1,2-dichloroethane slips in early in Chapter 2 . Then acetanilide and $p$-chloroacetanilide, with contrasting molecular arrangements in their centrosymmetric and noncentrosymmetric rhombic crystals, and chiral systems in general exemplified by 4 (bromomethyl)-6-(mercaptomethyl)[2.2] metacyclophane together with larger combined structures ease the reader towards quite elaborate chemical systems. Point groups are exemplified both by patterns and by molecules of greater or lesser complexity. The invaluable framework embodied in the valence shell electron pair repulsion model is discussed in some detail.

Group theory employing matrices is included, complete with a brief introduction to matrix manipulation, irreducible representations and character tables. Symmetry rules in vibrations precede electronic structure and symmetry in wave mechanics, and consideration of reaction mechanisms; symmetry rules for the reac-

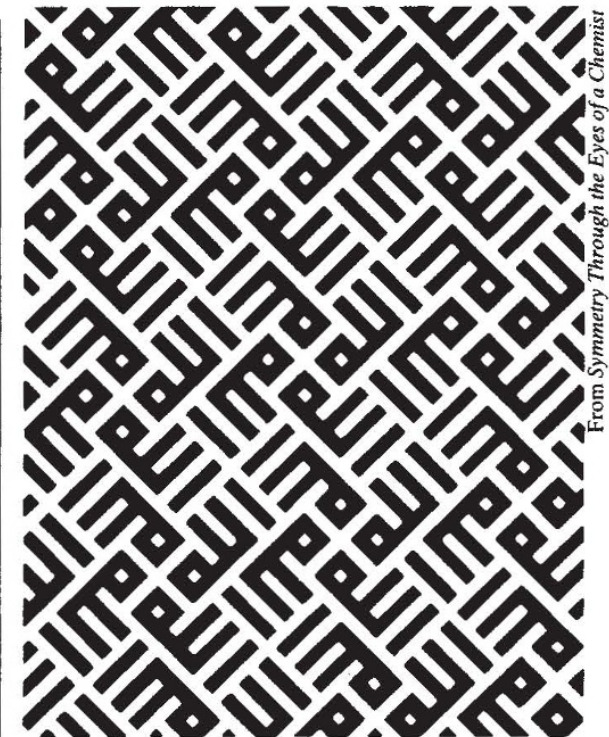

Period return - drawing, by the crystallog. rapher Khudu Mamedov, of the decoration on a mausoleum in Badra, Azerbaidzhan, in which the basic motif is the word Allah.

tion coordinate are summarized and the requirements of orbital symmetry, following the views of Fukui and of Woodward and Hoffman, are exemplified in numbers of simple examples. Space-group symmetries in infinite systems are addressed largely by reference to non-chemical examples, and crystals and crystal groups follow, to give all the applications of symmetry in chemistry conceivable (to me).

This pleasant evocation of symmetry applications is accomplished with continued reference to up-to-date chemistry. Thus I find a recent and not entirely welcome reference to the probable nonlinearity of gaseous transition metal dihalides: gone the simple coulomb view of bonding here, together with some cherished but now invalidated preconceptions.

The only non-chemical importations which in my view do not succeed are the passages from fellow-Hungarian writers. In these, verbal dualities and ambiguities of interpretation are explored, but out of context and in what seem contrived circumstances.

The margins take one-third of each page and attractively accommodate smaller diagrams, or the legends to larger textual ones, or otherwise simply present an aspect of spaciousness. Such extravagant counter-austerity (not of course new) will undoubtedly spread.

Almost education by stealth, certainly education by aesthetic appeal, the whole exercise is epitomized in the quoted words of Coulson: "Symmetry is important, but it is not everything.... It is when symmetry interprets facts that it serves its purpose because it links our study of chemistry with another world, [that] of the human spirit"

David R. Rosseinsky is a Reader in the Department of Chemistry, University of Exeter, Exeter EX $4 Q Q$, UK 